\title{
The effect of a nutritionally-balanced cassava (Manihot esculenta Crantz) diet on endocrine function using the dog as a model 2. Thyroid
}

\author{
BY BERYL P. KAMALU \\ Department of Veterinary Pathology and Microbiology, University of Nigeria, Nsukka, Nigeria \\ AND JULIUS C. AGHARANYA \\ Department of Chemical Pathology, College of Medicine, University of Nigeria, Enugu Campus, \\ Nigeria
}

(Received 9 October 1989 - Accepted 3 August 1990)

\begin{abstract}
Growing dogs were divided into three groups and were fed on nutritionally-balanced diets. Control dogs were fed on a rice diet, the cassava (gari) group ate a diet in which gari provided the carbohydrate source, while the rice + cyanide group consumed the rice diet to which hydrocyanic acid (equivalent to that present in gari) was added. Each group consumed its diet for 14 weeks, during which plasma thiocyanate concentration and total serum triiodothyronine $\left(T_{3}\right)$ were monitored. At the end of the experiment the concentrations of the plasma free amino acids phenylalanine and tyrosine, the thyroid weights and histology were determined. While plasma thiocyanate remained undetectable in control dogs, animals consuming both gari and rice + cyanide generated significant amounts. In the control dogs and the gari group, total serum $T_{3}$ increased $\mathbf{4 0}$ and $38.8 \%$ respectively from the basal level by the end of the period $(P<0.02)$. In contrast there was a decrease in $T_{3}$ by $36 \%$ in the dogs fed on rice + cyanide $(P<0.05)$. This group also showed significant thyroid enlargement and a histological picture consistent with parenchymatous goitre, whereas the gari group was essentially normal. The relatively low mean thyroid weight, the rise in total serum $T_{3}$ level and the normal histological appearance of the gland indicate that dogs that consumed the gari diet were essentially normal with respect to their thyroid function, in spite of their high blood thiocyanate content. In contrast, dogs that consumed rice with cyanide suffered from hypothyroidism and goitre. It is suggested that the gari diet, despite generating thiocyanate endogenously, when taken in a nutritionally-balanced diet with high-quality animal protein, has no deleterious effects on thyroid function.
\end{abstract}

Thyroid: Cassava diet: Dog

Most of the cyanide released from the cyanogenic glucoside of cassava, linamarin, is converted to thiocyanate by the enzyme rhodanese (thiosulphate:cyanide sulphurtransferase; EC 2.8.1.1) (Cosby \& Summer, 1945). Thiocyanate is a well-recognized goitrogen which acts by inhibiting the trapping of iodine by the thyroid gland, thereby depressing thyroid hormone synthesis and thyroid function.

The role of food goitrogens as possible contributory factors in endemic goitre and cretinism has engaged the attention of several researchers. Studies have suggested that ingestion of cassava increases thiocyanate formation in humans (Ekpechi et al. 1966; Ekpechi, 1967; Bourdoux et al. 1978) and animals (Osuntokun, 1970). Although cassava is consumed on a large scale within the tropics, goitre and cretinism are not found in all populations whose staple food is cassava. Delange et al. (1982) have suggested that the method of processing cassava, the iodine content of water and diet, and protein-energy malnutrition are some of the nutritional prerequisites to cassava toxicity. Nwokolo et al. (1966) found high incidence of goitre among people who consumed unfermented, dried, 
powdered cassava, in which form the cassava is said to have high levels of residual cyanogenic glucosides. It is known that metabolism of hydrocyanic acid to thiocyanate occurs at the expense of sulphur-containing amino acids.

Giesecke (1985) demonstrated that the dog is the species most similar to man in this respect. Miller et al. (1964) reported that the thyroid gland of the dog is subject to all pathological conditions known to man. The dog, therefore, appears to be a better animal model than the rat for studying the pathologies seen in man. The purpose of the present study was to investigate the effect of a nutritionally-balanced cassava (gari) diet on the thyroid gland of growing dogs.

MATERIALS AND METHODS

Animals

Management of the animals and diets fed were as described by Kamalu (1991).

\section{Biochemistry}

Total serum triiodothyronine $\left(\mathrm{T}_{3}\right)$ was measured during the pre-experimental period and then at weeks 3, 5, and 14 by the enzyme-linked immunosorbent assay (ELISA), using immunodiagnostic kits supplied by Boehringer Mannheim (Germany). Plasma phenylalanine and tyrosine were determined from pooled samples taken at the end of the experimental period using a Beckman $121 \mathrm{M}$ amino acid analyser.

\section{Thyroid weights and histopathology}

The dogs were anaesthetized with chloroform and then exsanguinated. The two lobes of the thyroid gland were removed and weighed. Pieces of the thyroid gland were fixed in buffered formalin $(100 \mathrm{ml} / \mathrm{l})$, routinely processed, and embedded in paraffin wax. Sections were cut at $5 \mu \mathrm{m}$ thickness, stained with haematoxylin and eosin and examined by light microscopy.

\section{Statistics}

Statistical analysis was performed using Duncan's multiple range test and Student's $t$ test, and the results presented as means with their standard errors except where otherwise stated.

\section{RESULTS}

\section{Animals}

Although there was a smaller weight gain in the dogs fed on rice + cyanide, all the dogs remained clinically healthy for the duration of the experiment.

\section{Biochemistry}

Whereas thiocyanate concentration remained undetectable throughout the period of the study in animals fed on the rice diet, feeding of gari and rice + cyanide caused significant elevations (Kamalu, 1991).

Dietary treatments produced a differential effect on thyroid weights and total serum $T_{3}$ concentrations (Table 1). The gari group had a significantly higher $T_{3}$ level than the control and rice + cyanide groups at the beginning of the study (zero week) $(P<0.05)$. However, the differences disappeared by week 3 . After week 3 there was an increase in dogs fed on the rice diet and the gari diet. $T_{3}$ concentrations increased steadily in the rice group throughout the period, reaching a level of 1.25 (SE 0.05) nmol/l at the end of the 14 th week representing an increase of $40 \%$ over the basal level 0.9 (SE 0.09$) \mathrm{nmol} / 1(P<0.02)$. In the gari group, $\mathrm{T}_{3}$ initially decreased from 1.28 (SE 0.16$) \mathrm{nmol} / 1$ (basal level) then increased after 
Table 1. Effect of dietary treatment on thyroid weights and total serum triiodothyronine $\left(T_{3}\right)$ concentration

(Values are means with their standard errors for six dogs)

\begin{tabular}{|c|c|c|c|c|c|}
\hline \multirow[b]{2}{*}{ Week } & \multirow{2}{*}{$\begin{array}{l}\text { Dietary } \\
\text { groups\$ }\end{array}$} & \multicolumn{2}{|c|}{$\begin{array}{l}\text { Thyroid wt } \\
\text { (g/kg body-wt) }\end{array}$} & \multicolumn{2}{|c|}{$\begin{array}{c}\text { Total serum } \\
(\mathrm{nmol} / \mathrm{l})\end{array}$} \\
\hline & & Mean & $\mathrm{SE}$ & Mean & SE \\
\hline 0 & $\begin{array}{l}\text { Rice } \\
\text { Cassava (gari) } \\
\text { Rice + cyanide }\end{array}$ & & & $\begin{array}{l}0.90 \\
1.28 \\
0.87\end{array}$ & $\begin{array}{l}0.09 \\
0.16 \\
0.08\end{array}$ \\
\hline 3 & $\begin{array}{l}\text { Rice } \\
\text { Cassava (gari) } \\
\text { Rice + cyanide }\end{array}$ & & & $\begin{array}{l}1 \cdot 05 \\
1 \cdot 18 \\
0 \cdot 90\end{array}$ & $\begin{array}{l}0.09 \\
0.02 \\
0.15\end{array}$ \\
\hline 5 & $\begin{array}{l}\text { Rice } \\
\text { Cassava (gari) } \\
\text { Rice + cyanide }\end{array}$ & & & $\begin{array}{l}1 \cdot 14 \\
1 \cdot 87 \\
0 \cdot 90\end{array}$ & $\begin{array}{l}0.08 \\
0.06 \\
0.12\end{array}$ \\
\hline 14 & $\begin{array}{l}\text { Rice } \\
\text { Cassava (gari) } \\
\text { Rice + cyanide }\end{array}$ & $\begin{array}{l}173 \\
119 \\
212^{*}\end{array}$ & $\begin{array}{l}13 \cdot 3 \\
13 \cdot 0 \\
38 \cdot 5\end{array}$ & $\begin{array}{l}1.25 \ddagger \\
1.78 \ddagger \\
0.56 \dagger\end{array}$ & $\begin{array}{l}0.05 \\
0.04 \\
0.08\end{array}$ \\
\hline
\end{tabular}

* Mean values were significantly different from those of cassava (gari) group: $P<0.005$.

+ Mean values were significantly different from those of rice group: $P<0.05$.

$\$$ Mean values were significantly different from basal (zero week) level: $P<0.02$.

$\S$ For details, see p. 366.

week 3 to 1.78 (SE 0.41$) \mathrm{nmol} / 1$ at the end of the study, representing an increase of $38.8 \%$ over the basal level $(P<0.02)$. $\mathrm{T}_{3}$ levels remained unchanged up to the 5 th week in the animals fed on rice + cyanide. By the end of the experiment, the levels had dropped from 0.87 (SE 0.09$) \mathrm{nmol} / \mathrm{l}$ in the basal level to 0.56 (SE 0.08 ) nmol/l, representing a $36 \%$ decrease $(P<0.05)$. This value was significantly lower than the corresponding values in the dogs fed on rice or gari $(P<0.05)$.

Because of the known effect of the thiocyanate ions on the thyroid gland, plasma thiocyanate and total serum $\mathrm{T}_{3}$ concentrations were subjected to correlation analysis. $\mathrm{A}$ negative correlation was obtained (Fig. 1) showing that $T_{3}$ decreases as thiocyanate increases.

Measurement of plasma free phenylalanine and tyrosine concentrations showed that there was a greater accumulation of the two amino acids in animals fed on rice + cyanide compared with the other two groups (Table 2).

\section{Thyroid weights and histopathology}

The mean thyroid weights after 14 weeks of dietary treatment were $174 \cdot 3$ (SE 13.3), 119 (SE 13.0 ) and 212 (SE 38.5) g/ kg body-weight for the rice, gari and rice + cyanide groups respectively (Table 1). Although the initial weights of the glands could not be determined, these findings showed significant thyroid enlargement in the rice + cyanide group compared with the gari group, even though neither of them was significantly different from that of the rice group (Table 1 ).

In the group of animals fed on the rice diet, the lumina of most of the follicles were large; most follicles contained colloid which stained slightly basophilic in some cases. The epithelium of the colloid-filled follicles was cuboidal (Plate 1), but that of empty or partially-filled ones was columnar. There was desquamation of columnar epithelial cells into the lumina of the empty follicles. 


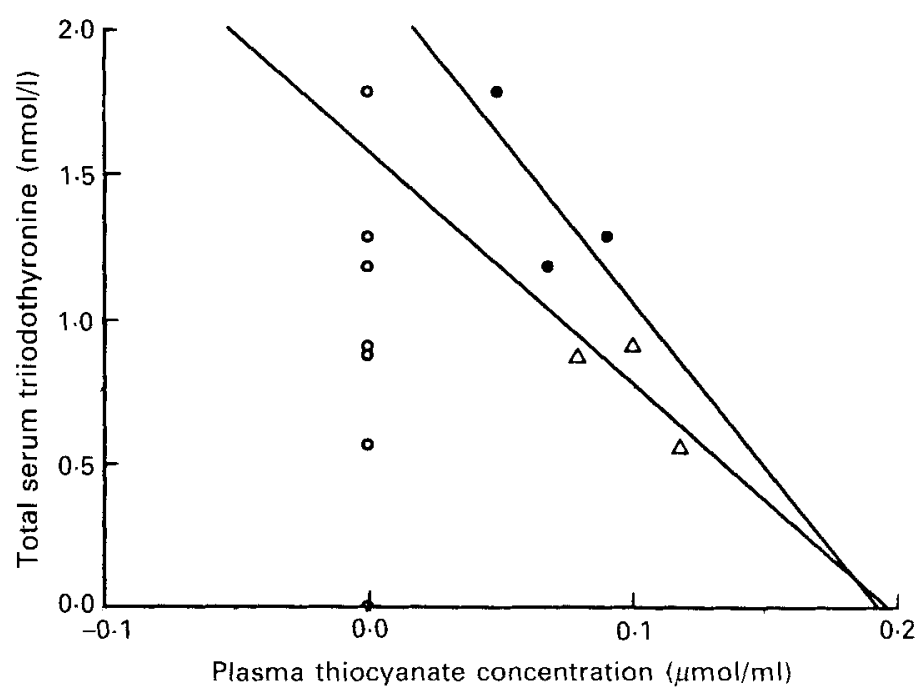

Fig. 1. Linear correlation between plasma thiocyanate and total serum triiodothyronine concentration. ( $O$ ) Dogs fed on control diet; (O) dogs fed on cassava (gari) diet; $(\triangle)$ dogs fed on rice + cyanide diet. Cassava (gari), $y=2.199-11.378 x, R^{2}=-0.559$, Rice + cyanide, $y=1.5741-8.028 x, R^{2}=-0.692$. For details of dietary regimen, see p. 366 .

Table 2. Concentration of plasma free phenylalanine and tyrosine in growing dogs after 14 weeks on experimental diets (nmol/l)

\begin{tabular}{|c|c|c|c|}
\hline \multirow[b]{2}{*}{ Amino acid* } & \multicolumn{3}{|c|}{ Dietary group $\dagger$} \\
\hline & Control & Cassava (gari) & Rice + cyanide \\
\hline Phenylalanine & $33 \cdot 7$ & $46 \cdot 6$ & $70 \cdot 8$ \\
\hline Tyrosine & $45 \cdot 2$ & $30 \cdot 7$ & 66.9 \\
\hline
\end{tabular}

* Amino acids were measured using pooled plasma for each group.

$\uparrow$ For details, see p. 366 .

In the group of animals fed on the gari diet, all the follicles contained colloid. The epithelial cells lining the colloid-filled follicles were low cuboidal (Plate 2), whereas those of follicles with scanty amounts of colloid were also cuboidal but larger than those of the follicles filled with colloid. There was no desquamation of the epithelial cells into the lumina of the follicles.

In the group of animals fed on rice + cyanide, the lumina of the follicles varied greatly in size. Colloid was present in only very few follicles and this was pale-staining and tended to be slightly basophilic. The follicles had much thicker walls than those of any other group and this was due to an increase in the number of layers of cells which formed the walls. The cells in the thickened walls were cuboidal (Plate 3). There was desquamation of epithelial cells into the lumina of empty follicles.

\section{DISCUSSION}

The present study has demonstrated that linamarin, the cyanogenic glucoside of cassava (gari) is metabolized in the dog to release $\mathrm{HCN}$ which in turn generates thiocyanate just as the HCN added to the diet. This observation is in support of the findings of other workers. 
Animals fed on the rice diet to which cyanide was added displayed a number of peculiar biochemical and histological changes. There was a significant thyroid enlargement with higher mean thyroid weights together with depressed mean total serum $T_{3}$ concentration. The histological picture suggests that the observed enlargement was due to hyperplasia of thyroid follicular cells resulting in an increase in the parenchyma of the gland. These features are consistent with parenchymatous goitre, the most common type of goitre found in the dog (Miller et al. 1964). All these changes confirm the goitrogenic action of the high plasma thiocyanate found in these animals. This finding is in agreement with previous observations. Sihombing et al. (1971) showed that administration of thiocyanate to pigs produced thyroid enlargement. Similar effects have been observed in rats (Ekpechi et al. 1966; Langer, 1966; Van der Velden et al. 1973).

The accumulation of plasma phenylalanine and tyrosine in the animals fed on rice + cyanide suggests that these amino acids were not being utilized to the same extent as that of animals fed on the other diets. The reason for this is not quite clear but appears to be related to the decrease of thyroid hormone formation. Although tyrosine is required for the synthesis of thyroglobulin, the precursor of thyroid hormones $\left(\mathrm{T}_{3}\right.$ and thyroxine $\left.\left(\mathrm{T}_{4}\right)\right)$, both tyrosine and its precursor phenylalanine serve a variety of other metabolic roles in the body.

Although feeding of gari led to the formation of $\mathrm{HCN}$, this did not mimic the free cyanide in producing the same biochemical and histopathological changes as observed in animals fed on diets of rice + cyanide. The plasma thiocyanate level was much lower in the gari group even though both diets contained equivalent amounts of $\mathrm{HCN}$. Total serum $\mathrm{T}_{3}$ rose by $38.8 \%$ above the basal value within 14 weeks, (an increase that was similar to that of the control group over the experimental period), compared with a drastic $(36 \%)$ fall in the rice + cyanide group. These observations, together with the normal histological picture and low mean thyroid weight, suggest that these animals were essentially normal with respect to their thyroid function in the presence of high plasma thiocyanate concentrations. This paradoxical finding raises the question as to the goitrogenic activity of the thiocyanate formed from gari and the nutritional factors predisposing to cassava toxicity.

Our results support the finding that several nutritional factors, especially the availability of $I$ as well as the nutritional status of the individuals, play a major role in determining the antithyroid activity of cassava (Delange et al. 1982). Baker (1936) found that added I completely reversed the goitrogenic effect of thiocyanate in rats. In order to supplement the relatively poor crude protein (nitrogen $\times 6 \cdot 25)$ content of cassava $(16 \mathrm{~g} / \mathrm{kg}$ compared with $75 \mathrm{~g} / \mathrm{kg}$ in rice (Food and Agriculture Organization, 1970)), it was necessary to increase the quantity of lean meat in the gari diet. Thus, the dogs consuming the gari diet derived a greater proportion of their protein from animal muscle.

It, therefore, appears that the greater quantity of animal muscle, a rich source of $I$, supplied a greater amount of I that was able to overcome the inhibitory effects of thiocyanate.

Although the animals remained clinically healthy throughout the period, gari-fed dogs exhibited a far superior state of health as shown by their higher weight gain throughout the experimental period, compared with the rice+cyanide group which suffered from hypothyroidism and goitre. In humans, endemic goitre is associated with impaired thyroid functions, although $\mathrm{T}_{3}$ and $\mathrm{T}_{4}$ may be normal (Udeozo \& Agharanya, 1986). Cassava toxicity is known to be more pronounced in the presence of severe iodine deficiency (Delange et al. 1973; Bourdoux et al. 1978) and protein malnutrition (Delange et al. 1982; Cliff et al. 1985; Frakes et al. 1986). The relatively better state of health and freedom from thyroid dysfunction enjoyed by the gari-fed dogs may be attributable to the nutritionallybalanced gari diet, especially the balance between I supply and thiocyanate content of the 
cassava-based diet. In humans, however, these nutritional prerequisites alone may not explain why gari consumption does not induce endemic goitre in all populations in which a cassava-based diet is the staple food, given the chronic low protein and energy intake in tropical regions. Other factors, including genetic predisposition, may come into play (Bayoumi et al. 1988).

The authors wish to acknowledge $\mathrm{Mr}$ E. Onouha and $\mathrm{Mr} \mathrm{P}$. Obo, Department of Veterinary Pathology and Microbiology, University of Nigeria, Nsukka, and the staff of The Royal Veterinary College, London, for their assistance.

\section{REFERENCES}

Baker, M. H. (1936). The blood cyanates in the treatment of hypertension. Journal of the American Medical Association 106, 762-767.

Bayoumi, R. A., Taha, T. S. \& Saha, N. (1988). Study of possible genetic predisposition to endemic goitre among the Fur and Baggara tribe of the Sudan. Human Heredity 33, 8-11.

Bourdoux, P., Delange, F., Gerard, M., Mafuta, M., Hanson, A. \& Ermans, A. M. (1978). Evidence that cassava ingestion increases thiocyanate formation: a possible etiologic factor in endemic goitre. Journal of Clinical Endocrinology and Metabolism 46, 613-621.

Cliff, J., Lundqvist, P., Martensson, J., Rosling, H. \& Sorbo, B. (1985). Association of high cyanide and low sulphur intake in cassava-induced spastic paraparesis. Lancet ij 1211-1213.

Cosby, E. L. \& Summer, J. B. (1945). Rhodanese. Archives of Biochemistry 7, 457-460.

Delange, F., Bourdoux, P., Colinet, E., Courtois, P., Hennart, P., Lagasse, R., Mafuta, P., Seghers, P., Thilly, C., Vanderpas, J., Yunga, Y. \& Ermans, A. M. (1982). Nutritional factors involved in the goitrogenic action of cassava. In Cassava Toxicity and Thyroid: Research and Public Health Issues. Proceedings of a Workshop, Ottawa [F. Delange and R. Ahluwalia, editors]. International Development Research Centre Monograph 207e, pp. 17-26. Ottawa: International Development Research Centre.

Delange, F., Van der Velden, M. \& Ermans, A. M. (1973). Evidence of an antithyroid action of cassava in man and animals. In Chronic Cassava Toxicity. Proceedings of an Interdisciplinary Workshop, London. [B. Nestel and R. MacIntyre, editors]. International Development Research Centre Monograph 0103, pp. 147-151. Ottawa: International Development Research Centre.

Ekpechi, O. L. (1967). Pathogenesis of endemic goitre in eastern Nigeria. British Journal of Nutrition 21, 537-545.

Ekpechi, O. L., Dimitriadou, A. \& Fraser, R. (1966). Goitrogenic activity of cassava (a staple Nigerian food). Nature 210, 1137-1138.

Food and Agriculture Organization (1970). Amino acid content of foods and biological data on proteins. Nutritional Studies No. 24, Rome: FAO.

Frakes, R. A., Sharma, R. P., Willhite, C. \& Gomez, G. (1986). Effect of cyanogenic glycosides and protein content in cassava diets on hamster prenatal development. Fundamental Applied Toxicology 7, 191-198.

Giesecke, D. (1985). Species differences relevant to nutrition and metabolism research. In Clinical Nutrition and Metabolic Research. Proceedings of the 7th Congress of the European Society of Parenteral and Enteral Nutrition, Munich, (G. Dietze, A. Griinert, C. Kleinberger and C. Wolfram, editors) pp. 311-328. Basel: Karger.

Kamalu, B. P. (1991). The effect of a nutritionally-balanced cassava (Manihot esculenta Crantz) diet on endocrine function using the dog as a model 1. Pancreas. British Journal of Nutrition 65, 365-372.

Langer, P. (1966). Antithyroid action in rats of small doses of some naturally-occurring compounds. Endocrinology 79, $117-122$.

Miller, M. E., Christensen, G. C. \& Evans, H. E. (1964). Anatomy of the Dog. Philadelphia: W. B. Saunders Co.

Nwokolo, C., Ekpechi, O. L. \& Nwokolo, U. (1966). New foci of endemic goitre in eastern Nigeria. Transactions of the Royal Society of Tropical Medicine and Hygiene 60, 97-108.

Osuntokun, B. O. (1970). Cassava diet and cyanide metabolism in Wistar rats. British Journal of Nutrition 24. $797-800$.

Sihombing, D. T. M., Cromwell, C. L. \& Hays, V. W. (1971). Effect of added thiocyanate and iodine to cornsoybean meal diet on performance and thyroid status of pigs. Journal of Animal Science 33, 1154.

Udeozo, I. O. K. \& Agharanya, J. C. (1986). Serum thyrotropin and thyroid hormone levels in normal subjects and those living in endemic goitre areas of Obudu, Nigeria. West African Journal of Medicine 5, 209-214.

Van der Velden, M., Kinthaert, J., Orts, S. \& Ermans, A. M. (1973). A preliminary study on the action of cassava on thyroid iodine metabolism in rats. British Journal of Nutrition 30, 511-517. 
British Journal of Nutrition, Vol. 65, No. 3

Plates $1 \& 2$
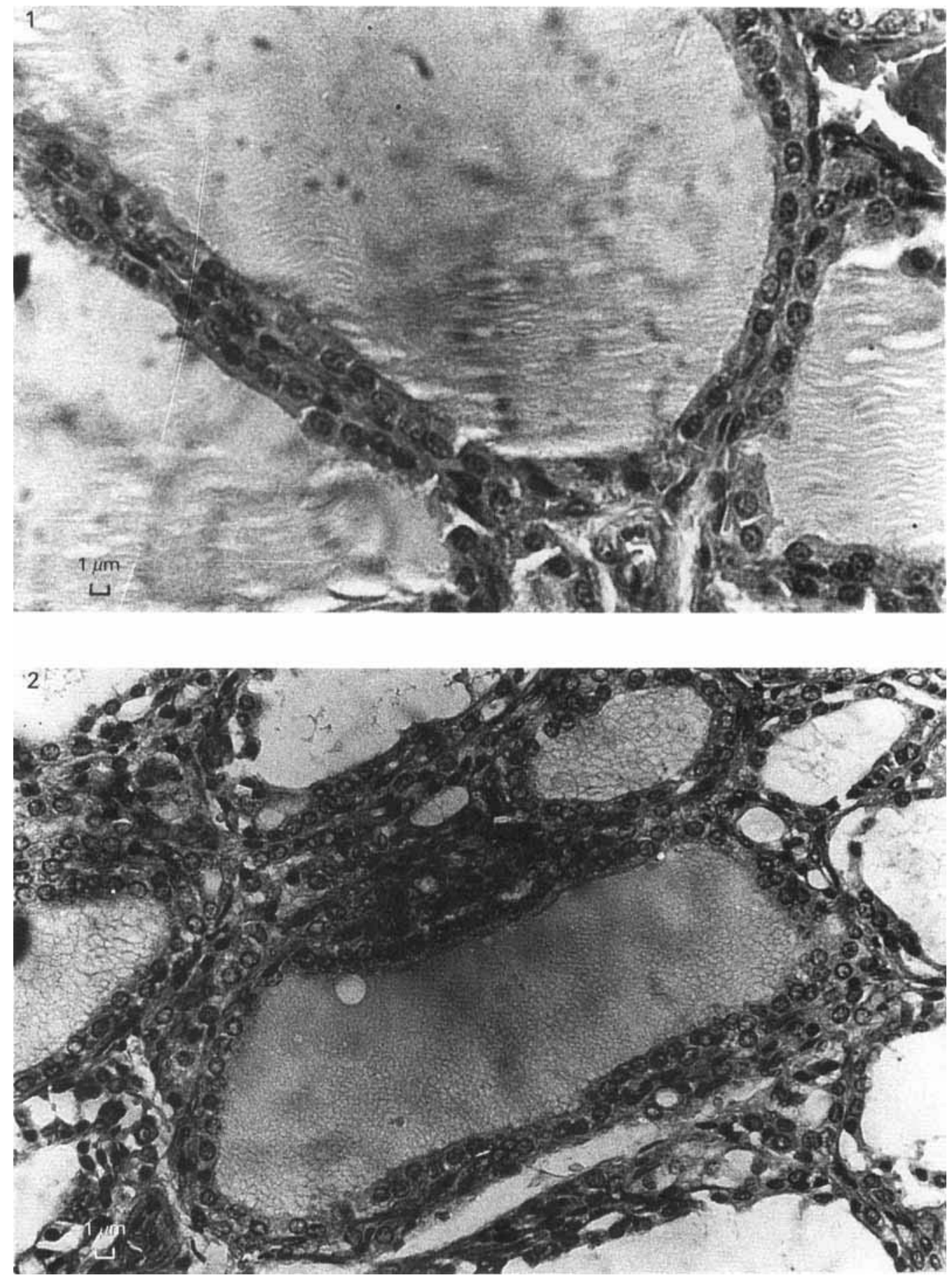


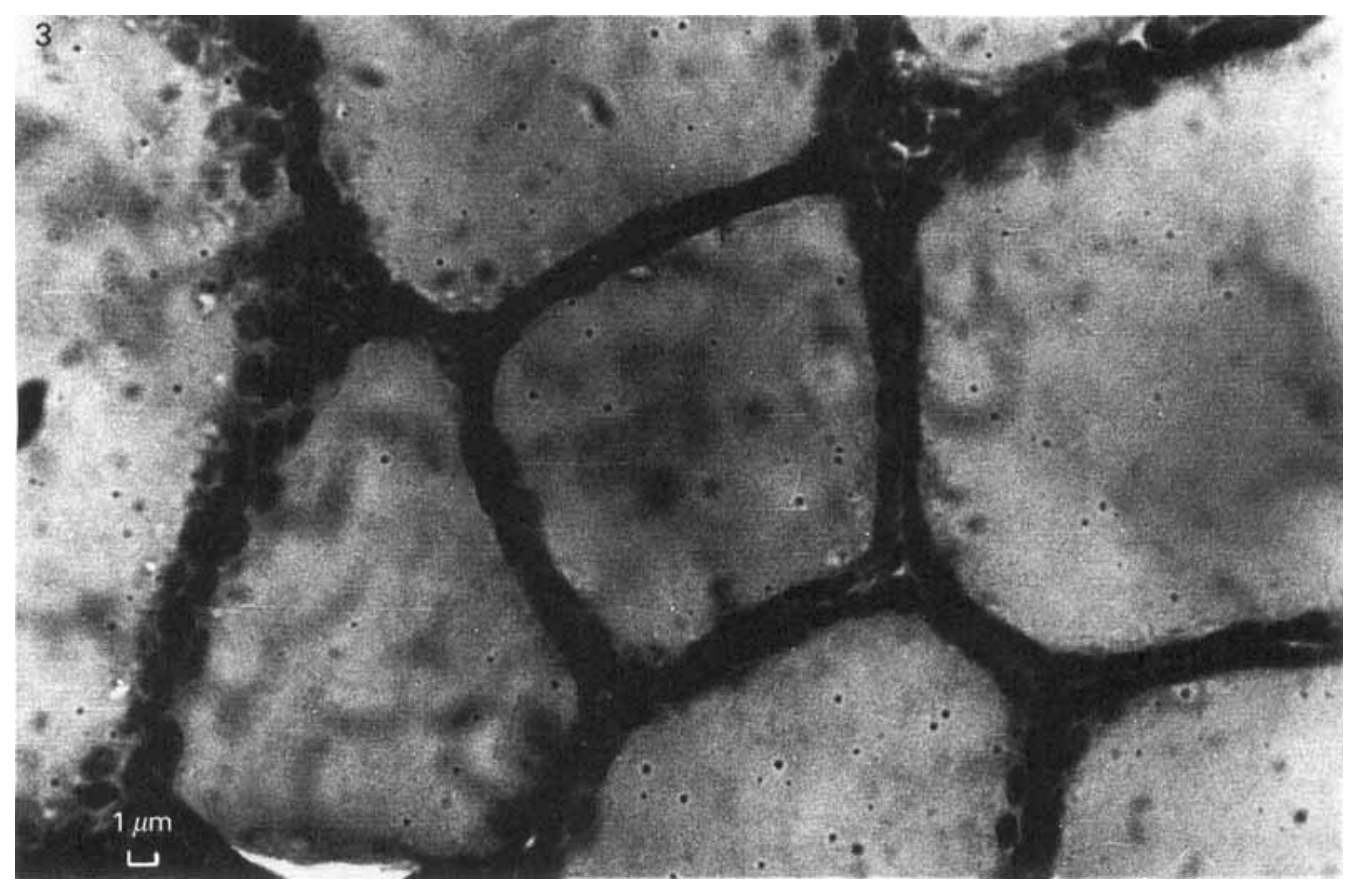




\section{EXPLANATION OF PLATES}

Plate 1. Thyroid gland of dog fed on control diet. Cuboidal epithelium lining follicle filled with colloid (haematoxylin and eosin). For details of diet see p. 366.

Plate 2. Thyroid gland of dog fed on cassava (gari) diet. Low cuboidal epithelium lining follicle filled with colloid (haematoxylin and eosin). For details of diet see p. 366.

Plate 3. Thyroid gland of dog fed on rice + cyanide diet. Several layers of cuboidal cells forming a thickened wall lining a follicle with colloid (haematoxylin and eosin). For details of diet see p. 366. 